\title{
IRRIGATION REQUIREMENT ESTIMATION USING VEGETATION INDICES AND INVERSE BIOPHYSICAL MODELING
}

\author{
Lahouari Bounoua $^{1}$, Marc L. Imhoff ${ }^{1}$, Shannon Franks ${ }^{2}$ \\ ${ }^{1}$ NASA's Goddard Space Flight Center, Biospheric Sciences Branch \\ ${ }^{2}$ SGT, Inc., NASA's Goddard Space Flight Center
}

\begin{abstract}
We explore an inverse biophysical modeling process forced by satellite and climatological data to quantify irrigation requirements in semi-arid agricultural areas. We constrain the carbon and water cycles modeled under both equilibrium, balance between vegetation and climate, and non-equilibrium, water added through irrigation. We postulate that the degree to which irrigated dry lands vary from equilibrium climate conditions is related to the amount of irrigation. The amount of water required over and above precipitation is considered as an irrigation requirement. For July, results show that spray irrigation resulted in an additional amount of water of $1.3 \mathrm{~mm}$ per occurrence with a frequency of 24.6 hours. In contrast, the drip irrigation required only $0.6 \mathrm{~mm}$ every 45.6 hours or $46 \%$ of that simulated by the spray irrigation. The modeled estimates account for $87 \%$ of the total reported irrigation water use, when soil salinity is not important and $66 \%$ in saline lands.
\end{abstract}

Index Terms - Irrigation modeling, semi-arid regions

\section{INTRODUCTION}

The world's population is increasing rapidly and agricultural food production must increase to keep up with the continuously growing demand. Agriculture is the world's largest water-use sector and has strong influence on the water cycle, especially in arid and semi-arid regions, through the extraction of ground water and diversion of surface water. Water seems abundant on our planet; however, less than $1 \%$ of the world's liquid freshwater is available for human use and about $70 \%$ of it is used for irrigation of agriculture [1]. The amount of water withdrawn annually for agricultural use is over $1,500 \mathrm{~m}^{3}$ per person in most of Central Asia (CA) while it is less than $20 \mathrm{~m}^{3}$ per person in many African countries [2]. In arid and semi arid regions such as in the Middle East (ME) and North Africa (NA), the water withdrawal as percentage of the total renewable water resource is more than $50 \%$ [2].

The scarcity of fresh water is already the subject of conflicts around the world where political boundaries dissect natural watersheds, aquifers and river flow. This source of conflict is expected to be more acute in the near future as climate changes, population increases and agricultural and water demand increases for the same or decreasing precipitation amounts. For these areas in particular, where the water supply and demand are out of balance, variations in regional climate can have potentially predictable environmental and socio-economic consequences.

We develop an inverse modeling methodology using a biophysical model forced by observed satellite and climate data to quantify the irrigation water demand in semi-arid areas. We constrain the carbon and water cycles modeled under both equilibrium, balance between vegetation density and prevailing local climate, and non-equilibrium, water added through irrigation, conditions (Fig.1). We postulate that the degree to which irrigated dry lands vary from equilibrium climate conditions is related to the amount of irrigation water used. The amount of water required over and above precipitation, if any, is considered as the minimum physiological water requirement. The total water requirement is then obtained as the sum of the minimum physiological water requirement and the losses due to water transport, delivery method and evaporation. Several efficiency factors, relating to these losses, apply when computing the total water requirement.

\section{THE MODEL}

We used the Simple Biosphere model-SiB2 of [3]. In $\mathrm{SiB} 2$, the vegetation distribution [4] as well as its spatial and temporal phenology is described using satellite observations. Each vegetation class is assigned a set of parameters including: 1) time-invariant parameters such as physiological, morphological and optical properties and 2) time-varying phenological parameters describing the vegetation's seasonal evolution. We obtain Leaf Area Index (LAI) from the MODIS instrument (MOD15A2) to derive the biophysical fields such as the fraction of photosynthetically active radiation (FPAR), needed for the model [5]. FPAR is used directly in an integrated photosynthesis-conductance model to calculate the photosynthesis and transpiration rates. LAI and FPAR are prescribed from satellite; they affect the surface water and energy balance but do not respond to it. The LAI is used in 
the calculation of albedo as well as the transpiration and interception loss components of the evapotranspiration.

\section{METHODOLOGY}

We test this methodology over known semi-arid agricultural lands, with no summer rainfall, in NA and South CA, spanning a wide range of cultures from leguminous to cotton. Although these regions fall under the climate classification of semi-arid to arid zones, they differ in their soil properties and quality, amount of precipitation, salinization level, and irrigation practices. For this study we test our method against reported data related to cultivation of leguminous over NA and cotton over south CA.

The method reposes on the realistic assumption that, in its "natural" state vegetation density is in quasi-equilibrium with its local climate, soil and nutrient resources [5]. Satellite driven land surface models, such as SiB2 and others, have proven useful for quantifying water and carbon flux for vegetated land cover in this equilibrium state $[6,3]$. In $\mathrm{SiB} 2$, the photosynthetic activity of the quantity of living vegetation prescribed from satellite data is modulated by the local climatology in a way that is consistent with observations and ecological theory of resource use efficiency [7]. However, irrigated agricultural lands in arid and semi-arid areas are not in equilibrium with local climate. As such, despite the high satellite vegetation index (VI) observed for these areas, the modeled photosynthetic activity will be "suppressed" by the lack of adequate precipitation provided by that climate $[8,5,9]$. We postulate that the degree to which the satellite observed VI of irrigated lands vary from what would be expected under equilibrium conditions is related to the amount of irrigation water used. Given the cover type and its physiological attributes, by inverting the biophysical model, it is possible to explore the relationship between observed vegetation leaf area index (LAI) in the equilibrium state and the amount of additional water required to deviate from it by increasing the water input in the model as a unique function of the root zone water content. Water is added using two delivery methods: The first method adds water on top of the canopy and simulates the spray irrigation while the second method allows water to be applied directly into the soil layer and serves as proxy for drip irrigation.

Other studies have also examined methodologies to map irrigated lands using remotely sensed temporal and spectral signatures associated with irrigated lands [10].

\section{RESULTS AND DISCUSSION}

In $\mathrm{SiB} 2$, water stress depends on the water content in the root zone, itself a function of the precipitation amount, soil physics and soil hydraulic properties. A value of 1 corresponds to no-stress while 0 represents maximum stress. When the soil water content in the root zone reaches a low

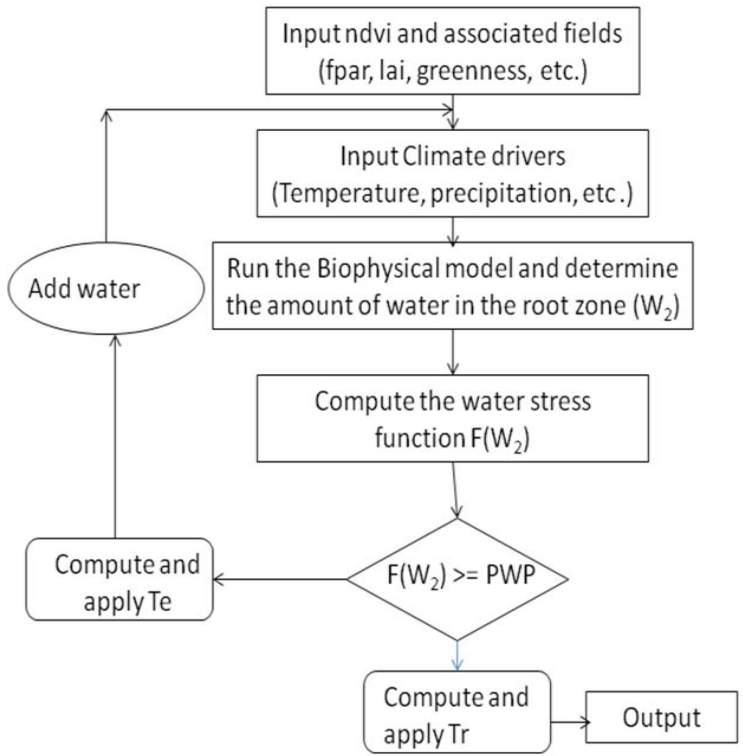

Figure 1: Iterative process for the determination of irrigation water. The baseline is the observed LAI from MODIS and local hourly observations, which includes precipitation. Water is added to minimize the water stress and maintain the balance between climate and observed LAI. Output is the total amount of water required to maintain that balance.

level threshold, the water stress function inhibits plant's photosynthesis, indicating disequilibrium between the satellite observed LAI and the amount of water in the root zone, and triggers the irrigation mechanism.

Figure 2 shows results from the modeling procedure averaged over multiple farms in the Mitidja basin (NA) [6] for both spray and drip irrigation schemes during the month of July. The spray irrigation has maintained a low stress level of about 0.9 and provided an average irrigation amount of $1.3 \mathrm{~mm}$ of water per occurrence with an average frequency of 24.6 hours. Since water is added directly on top of the canopy, it first saturates the canopy interception store, fills the surface layer store and then infiltrates into the root zone. If the infiltration rate is in excess of the infiltration capacity of the soil, the excess water contributes to surface runoff. As water is added, however, the moisture content in the root zone builds up and maintains values significantly higher than the control simulation, thus reducing the water stress. 

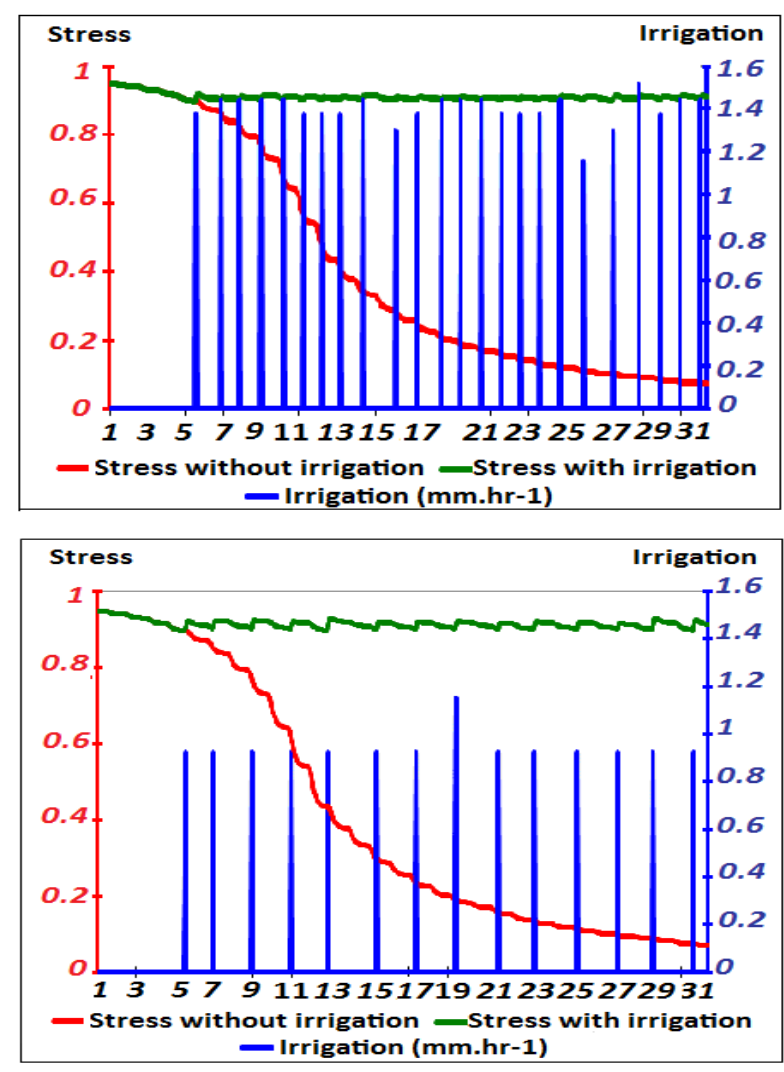

Figure 2: Water stress and irrigation for the control (red) and irrigation (green) simulations for the Mitidja basin in North Algeria. Top panel: spray irrigation and bottom panel: drip irrigation

The drip irrigation method reduced both the fluxes of water to the canopy and ground interception stores compared to the spray irrigation. It resulted in less frequent irrigation events, about once every 45.6 hours, with an average irrigation amount of $0.6 \mathrm{~mm}$ per occurrence, or about $46 \%$ of that simulated during the spray irrigation for July. The simulated monthly minimum physiological water requirement under this method for July is $9.8 \mathrm{~mm}$; a remarkable $29.5 \mathrm{~mm}$ less than the spray irrigation.

Since both the canopy and the ground are wet during and immediately after the irrigation, water is lost to the atmosphere through interception, especially from the canopy which is exposed to high air temperatures and vapor pressure deficit. This results in cooling and moistening the canopy air space which reduces the canopy transpiration and thus the irrigation efficiency. This effect is more evident during the spray irrigation; however at this small spatial scale evaporation does not have a significant effect on climate. Indeed, our modeling results indicate that at any time of the day; irrigation is more efficient at the beginning than at the end and during morning rather than afternoon. It is also shown that irrigation is more efficient during spring
Table 1: Modeled minimum physiological water requirements for 2008 site in North Africa (site1, size= 1ha, growing leguminous) and in Central Asia (site2, 100ha, growing cotton).Irrigation values are in $\left(\mathrm{m}^{3} \mathrm{ha}^{-1} \mathrm{yr}^{-1}\right)$

\begin{tabular}{|l|l|c|}
\hline Irrigation & \multicolumn{1}{|c|}{ Site 1 } & Site 2 \\
\hline Spray & $1170.00(61.5)$ & $4095.00(56.5)$ \\
\hline drip & $300(16)$ & $1365.00(19)$ \\
\hline reported & 1920.20 & $7000-7500$ \\
\hline
\end{tabular}

than summer when the evaporative demand is high (Fig. 3). We believe this is an important result that can be used to optimize productivity and reduce water use.

Our estimates for the minimum physiological water requirements are much lower than reported country-level total irrigation (table 1). The difference is due to several irrigation efficiency factors. Along with the minimum physiological water requirement, several efficiency factors apply when computing the total water use in agriculture [12] ranging from water transport (source to farm gate and farm gate to field), transpiration efficiency, consumptive efficiencies and water delivery method. When the transport (Tr) and the transpiration (Te) efficiencies are applied to the NA sites, the modeled total water requirement approaches $87 \%$ of the reported value. The remainder is partially attributable to yield efficiency. For this NA region, the transport efficiency has degraded severely since 2000, due to the aging of the system of irrigation and lack of maintenance leading to values around 50\% for 2006 [6]. In CA, however, where soil salinity is high, results are significantly different. When the efficiencies are applied, water requirement approached only $66.1 \%$ of the reported value. The large difference between the modeled and reported irrigation values in $\mathrm{CA}$ is believed to be largely

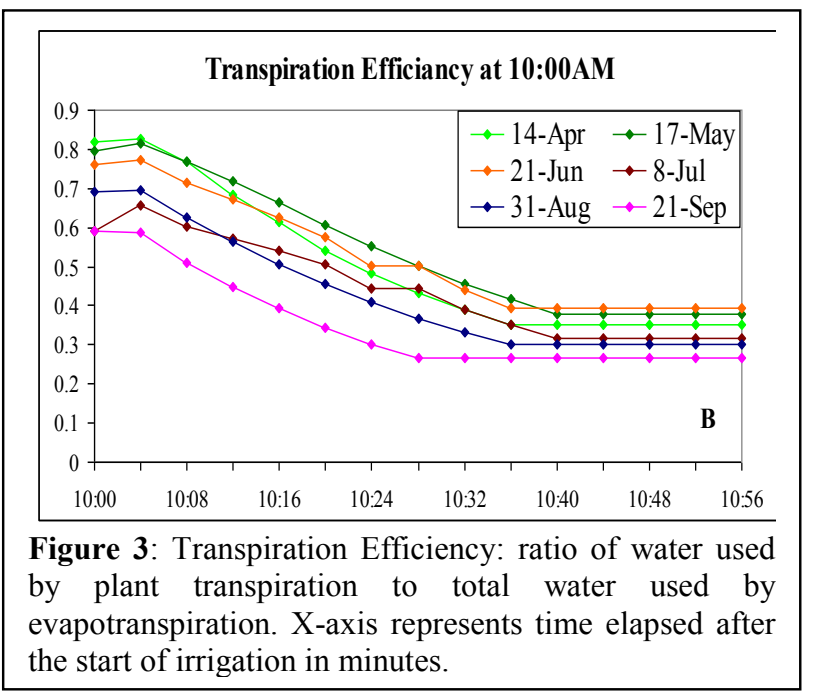


attributable to water delivery practices and soil salinity. In most of South CA, land flooding and furrow irrigation are common practices in large collective farms "Kolkhozes". Combined with severely degraded soils; these irrigation practices result in large amount of lost irrigation water (water not used by plants). For example, [13], report that in Turkmenistan, about $99 \%$ of the fields are irrigated by furrows and that the overall efficiency of irrigation systems is around $45 \%$ and results in annual losses of about $12 \mathrm{~km}^{3}$ of water that directly infiltrates the soil to feed the groundwater, raises the water table and intensifies the salt accumulation processes. Soil salinity is a major problem in agricultural lands, especially in South CA.

\section{CONCLUSION}

Combining satellite data and an inverse biophysical modeling methodology, we show that it is possible to remotely quantify the amount of water required for irrigation when the crop type is known. The model computes both the minimum physiological water requirement and the total water requirement including losses due to transportation, transpiration and delivery. The model is able to account for about $87 \%$ of the reported irrigation water use, when soil salinity is not important and $66 \%$ in saline lands. We estimate the minimum physiological water requirement during drip irrigation to be about $46 \%$ of that used during spray irrigation.

Within our modeling approach there are factors that can affect the results. Different biophysical models have different water stress functions and none is calibrated for all crop types. Therefore our results are dependent on the model used and our methodology requires more crop information to be implemented globally. Despite these issues, however, our results can be viewed as an ideal physiologically based target for irrigation efficiencies under well controlled conditions.

\section{REFERENCES}

[1] D. Molden, K. Frenken, R. Barker et al., Trends in water and agricultural development. A Comprehensive Assessment of Water Management in Agriculture. London, Earthscan, and Colombo: International Water Management Institute.

[2] AQUASTAT database, http://www.fao.org/nr/water/aquastat/water_use/index.stm (last accessed July 1st, 2010)

[3] P.J. Sellers and co-authors, "A revised land surface parameterization (SiB2) for atmospheric GCMs, Part 1: Model formulation," J. of Climate, vol. 9 (4), pp. 676-705, 1996a.
[4] R.S. Defries and J.R.G. Townshend, "NDVI-derived land cover classifications at a global scale," International Journal of Remote Sensing, vol. 15, pp. 3567-3586, 1994.

[5] L.R. Bounoua, S. DeFries, M. L. Imhoff, and M. K. Steininger, "Land use and local climate: A case study near Santa Cruz, Bolivia," Meteorol Atmos Phys. vol. 86, pp. 7385, 2004.

[6] R.E. Dickinson, "Modeling Evapotranspiration for ThreeDimensional Global Climate Models," In J. E. Hansen and T. Takahashi (Eds.), Climate Processes and Climate Sensitivity (pp. 58-72). Washington D.C: Geophysical Monograph 29, American Geophysical Union, 1984.

[7] I.R. Cowan, "Stomatal behavior and environment," Advances in Botanical Research, vol. 4, pp. 117-228, 1977.

[8] J. Pongratz, L. Bounoua, R.S. Defries, D.C. Morton, L.O. Anderson, W. Mauser, and C. Klink, "The impact of land cover change on surface energy and water balance in Mato Grosso, Brazil," Earth Interactions, vol. 10,pp. 1-17, 2006.

[9] M.L. Imhoff, L. Bounoua, W.T. Lawrence, D. Stutzer, and T. Ricketts, "The consequences of urban land transformation on net primary productivity in the United States," Remote Sensing of Environment, vol. 89, pp. 434443, 2004

[10] M. Ozdogan, and G. Gutman, "A new methodology to map irrigated areas using multi-temporal MODIS and ancillary data: An application example in the Continental US," Remote Sensing of Environment, vol. 112, pp. 35203537, 2008.

[11] K. Laoubi, and Y. Masahiro, "Management of Irrigation Schemes in Algeria," Environment, vol. 125, 2008. ISBN 978-1-84654-199

[12] T.C. Hsiao, P. Steduto, and E. Fereres, "A systematic and quantitative approach to improve water use efficiency in agriculture," Irrigation Science, vol. 25, pp. 209-231, 2007.

[13] Orlovsky and Orlovsky (2005), "Water resources of Turkmenistan. Use and conservation" (orlovsky@,bgumail.bgu.ac.il), pers. com., 2005 